\title{
The differences of body measurements in captive Sumatran elephant on different captivity management and sex
}

\author{
DENY SETYO WIBOWO ${ }^{1}$, ALEK IBRAHIM ${ }^{1}$, RINI WIDAYANTI ${ }^{2}$, WISNU NURCAHYO ${ }^{3}$, \\ MUHAMMAD WAHYU ${ }^{4}$, JOHAN R. MICHAUX ${ }^{5}$, HERY WIJAYANTO ${ }^{6, \bullet}$ \\ ${ }^{1}$ Veterinary Science Doctoral Program, Faculty of Veterinary Medicine, Universitas Gadjah Mada. J1. Fauna No. 2, Karangmalang, Sleman 55281, \\ Yogyakarta, Indonesia \\ ${ }^{2}$ Department of Biochemistry, Faculty of Veterinary Medicine, Universitas Gadjah Mada. Jl. Fauna No. 2, Karangmalang, Sleman 55281, Yogyakarta, \\ Indonesia \\ ${ }^{3}$ Department of Parasitology, Faculty of Veterinary Medicine, Universitas Gadjah Mada. Jl. Fauna No. 2, Karangmalang, Sleman 55281, Yogyakarta, \\ Indonesia \\ ${ }^{4}$ Veterinary Society for Sumatran Wildlife Conservation. Tanjung Sari, Medan Selayang, Medan 20154, North Sumatra, Indonesia \\ ${ }^{5}$ Conservation Genetics Research Unit of University of Liege. B-4000 Liege, Belgium \\ ${ }^{6}$ Department of Anatomy, Faculty of Veterinary Medicine, Universitas Gadjah Mada. Jl. Fauna No. 2, Karangmalang, Sleman 55281, Yogyakarta, \\ Indonesia. Tel.: +62-274-6492088, Fax.: +62-274-560861, `email: herykh@ugm.ac.id.
}

Manuscript received: 13 April 2021. Revision accepted: 9 June 2021.

\begin{abstract}
Wibowo DS, Ibrahim A, Widayanti R, Nurcahyo W, Wahyu M, Michaux RJ, Wijayanto H. 2021. The differences of body measurements in captive Sumatran elephant on different captivity management and sex. Biodiversitas 22: 2619-2624. Sumatran elephants are one of wild animals in Indonesia that currently received critically endangered status. This study aimed to measure the body size of both sexes of Sumatran elephants in the semi-captive (ECCs) and full captive (Zoo) management for conservation purposes. This study was conducted in ECCs in Sumatran island and Zoo on Java island. Body measurements (Chest Girth, Length, Height, Tarsal and Carpal Circumference) were collected from a total of 49 samples of captive Sumatran elephants (25 from EECs and 24 from Zoo). Data were analyzed using a completely randomized factorial design with different management and sex as the factors. The results showed that BL (304.92 vs 311.13$)$ and TC (76.44 vs 77.50) were significantly different $(\mathrm{P}<0.05)$ across captivity managements. Sex categories (male and female) showed significant results ( $\mathrm{P}<0.01)$ on CG (321.71 vs 302.46), BL (303.50 vs 272.49), BH (230.14 vs 208.23) and TC (82.29 vs 74.83). No interaction was identified between captive management and sex on body measurements. In conclusion, there were significant differences in body size of male and female elephants. This result contributed well-researched information to evaluate the conservation management based on body size and for further research on Sumatran elephant conservation.
\end{abstract}

Keywords: Body measurement, Captivity, Conservation, Sumatran elephant

\section{INTRODUCTION}

Asian elephant is widely distributed in South Asia, especially in Peninsular Malaysia, Sumatra, and Kalimantan (Borneo) (Wibowo et al. 2021). Sumatran elephant is one of Asian elephant subspecies labelled Critically Endangered $(C E)$ by International Union for Conservation of Nature (IUCN). Asian elephant spread in 13 states with current population estimated 45.000 elephants, and 15.000 elephants live in captivity (Sakamoto 2017). In Indonesia, the estimation of Sumatran elephant population ranged from 2400 to 2800 that spreading across seven province in Sumatra (Azmi and Gunaryadi 2011). The population of Sumatran elephants continue declining because of illegal hunting, human-elephant conflict and industrial plantation (Sulandri and Zein 2012). In Asia, elephant has been used for working animals in the logging industry, transportation, machines for war and as an object for cultural and religious reasons (Reilly and Sukatmoko 2002; Bansiddhi et al. 2018). Additionally, the elephants are privately used for circus troupes and zoos for tourism. From 1994 to 1998, the Indonesian Government decided to capture all non-viable wild populations and elephants inhabiting production forests (Tilson et al. 1993). This program successfully captured 715 wild elephants and relocated them into captivity to be trained, and approximately $30 \%$ of all captured elephants were brought to Way Kambas captivity facility (Tilson et al. 1993; Sulandri and Zein 2012). To prevent overcrowding in the existing facility, the elephants were transferred to the new facility in Sumatra island (government-owned) and zoos (privately owned) (Reilly and Sukatmoko 2002). Over time, many transmigrants come to Sumatra that eventually escalates the conflict between humans and wild elephants. This issue has encouraged the government to establish elephant training centers near the conflict areas and prevent human-elephant conflict using the trained captive elephant (Reilly and Sukatmoko 2002). Moreover, the captured wild problematic elephants used to be trained for some reason, such as logging activity, agriculture, and tourism (Reilly and Sukatmoko 2002).

Captive breeding is a place such as zoos or wildlife parks for the process of breeding, especially to preserve the endangered species that are threatened in the wild (Wakchaure and Ganguly 2016). In Indonesia, there are two types of facilities for elephants in captivity, Elephant 
Conservation Centers (ECCs) in Sumatra and Zoo that have different management. The government-owned ECCs apply semi-captive management while the Zoo implements fullcaptive management. Both managements offer humanelephant interactions, such as attending the training shows, hand feeding, walking with, and riding on the elephant (Rossman et al. 2017). However, the semi-captive management is slightly different - the elephants are less space-restrained than zoo-housed elephants, at least for a moment in a day (de Mori et al. 2019). The elephants are let free (usually foraging) without any imposed activity but remain under the supervision of mahout (de Mori et al. 2019). In Sumatra, elephants usually have free time to forage in the middle of the forest close to ECCs. This activity is referred to as free choice activity (FCA). FCA improves elepant's ability to explore and interact with their natural environment in a non-restricted way (Graham et al. 2018). It is crucial considering the welfare of and cognitive stimulation for the elephants. Semi-captive condition has a positive influence due to the probability of elephants to choose their own food and exhibit natural behavior without human intervention (Graham et al. 2018). Indeed, the captivity programs principle should aim at the creation and conservation of healthy, self-sustaining populations which resemble their wild environment both in behavior and genetics (Wakchaure and Ganguly 2016).

Body measurement of the animal is an important factor to optimize management in captivity (Wijeyamohan et al. 2012). Body growth of species is the important aspect to understand the life-history theory, which influences key life-history traits such as survival, development, and reproduction (Mumby et al. 2015b). Body parameters, such as height, girth and length are commonly used to measure immobilized animals (Chapman et al. 2016). Body size plays a significant role and demonstrates influential aspects of physiology, metabolic rate, reproduction, diet, morphology and dominance (Larramendi 2016). Additionally, information on individual body measurements is useful for medical treatment or intervention, to aid conservation efforts, to evaluate conservation management in captivity, and to study the behavior, ecology and evolution of animals (Chapman et al. 2016). Several body measurements such as chest girth, body length, and body height are correlated and feasible for predicting body weight (Ibrahim et al. 2020). Compiling data of the shoulder height and body mass in living elephants is a popular technique to predict the equations and applied in extinct taxa (Athanassiou 2012; Larramendi 2016; Jukar et al. 2018). It could be possible, because the relationship between shoulder height and body mass is well known among extant animals (Larramendi 2016). Methods to indirectly estimate the linear size measurement include photogrammetry, acoustic signals, footprint size, and basically, the observer estimations. Body measurement could estimate the animal's weight and it is the vital marker of body condition, especially for larger species, according to the management in captivity (Chapman et al. 2016). However, techniques using direct body measurements are not fully reliable for accuracy assessment. On the other hand, body growth among elephants is important to optimize captive management (Wijeyamohan et al. 2012). This study aimed to assess different body measurements of captive Sumatran elephants of different sexes (male and female) under different managements in captivity (semicaptive and captive). The result provides information on body measurements to obtain the accurate prediction of body weight and for conservation purposes.

\section{MATERIALS AND METHODS}

\section{Sample}

The research measured body size of 49 adult captive Sumatran elephants ( 14 males and 35 females) aged $>15$ years. The Sumatran elephants were distinguished by two captive managements, the semi-captive Elephant Conservation Centers (ECCs) and the full-captive zoo. We used 25 elephants from ECCs (Aceh and Riau Province) in Sumatran island and 24 elephants from the zoo (Gembira Loka Zoo, Borobudur Park and Safari Park).

This study had received an ethical clearance number 002.0/EC-FKH/Int./2019 issued by the Veterinary Medicine Ethical Clearance Committee, Universitas Gadjah Mada (UGM), Yogyakarta, Indonesia (accepted on March 18, 2019).

\section{Body measurements}

Body measurements of five parameters included chest girth (CG), tarsal circumference (TC), carpal circumference (CC), body length (BL), and body height (BH) obtained using tape $(\mathrm{cm})$. The body length was measured from the base of the neck to the fold of the tail. Chest girth was measured from behind the forelegs to ensure that it was not affected by inhalation. To measure body height (BH) we used a modified, expandable aluminum pole to ensure perpendicular measurements. Body height was measured from the scapula to the ground, but we ensured that elephants were in the normal standing position. Tarsal circumference and Carpal circumference were measured in the middle of os tarsal (hindfoot) and os carpal (forefoot) in normal standing position (right foot). The measurement of each parameter was repeated three times to avoid false measurement and to increase accuracy. The measurement was performed on the flat ground.

\section{Data analysis}

The data were subjected to randomized complete block design (RCBD) using SPSS software version 25 (IBM Inc, USA) to validate the normal data distribution. The analysis determined the effect of sex (male and female) and captive management (semi-captive and full captive) on the variable of body measurements. Additionally, their interactions on the variable of body measurements (CG, BH, BL, TC, and CC) of Sumatran elephant were investigated. 


\section{RESULTS AND DISCUSSION}

\section{Results}

The statistics and distribution of body measurements of Sumatran elephant are presented in Table 1, Figure 1, and Figure 2. Figure 1 shows the distribution of the Sumatran elephants' body size across different sexes. It appears that the average body sizes, both male and female, were almost the same as the median, reflecting the relatively identical amount of data below and above the median. It is indicative of normal distribution of body size across Sumatran elephants in this study.

The same pattern is observed in the body size of Sumatran elephants under different captive management (Figure 2). It appears that almost all the mean body sizes are almost identical to the median. These two figures illustrate that in this study there were no outliners for each body size.

Table 1. Body measurements (mean $\pm \mathrm{SD}$ ) of elephant on different sex and captive managements

\begin{tabular}{llllll}
\hline Variables & \multicolumn{1}{c}{ CG } & \multicolumn{1}{c}{ BL } & \multicolumn{1}{c}{ BH } & TC & CC \\
\hline Sex (P-value) & $0.004^{* *}$ & $0.007^{* *}$ & $0.000^{* *}$ & $0.000^{* *}$ & $0.596^{\mathrm{ns}}$ \\
Male & $321.71 \pm 25.02$ & $303.50 \pm 30.74$ & $230.14 \pm 11.25$ & $82.29 \pm 6.14$ & $79.79 \pm 4.00$ \\
Female & $302.46 \pm 20.51$ & $272.49 \pm 23.65$ & $208.23 \pm 12.32$ & $74.83 \pm 5.45$ & $78.69 \pm 14.14$ \\
Captive managements (P-value) & $0.118^{\text {ns }}$ & $0.032^{*}$ & $0.439^{\text {ns }}$ & $0.018^{*}$ & $0.119^{\text {ns }}$ \\
Semi-captive & $304.92 \pm 22.47$ & $291.56 \pm 35.74$ & $216.24 \pm 15.67$ & $76.44 \pm 6.79$ & $75.04 \pm 6.27$ \\
Full captive & $311.13 \pm 24.29$ & $270.71 \pm 14.65$ & $212.67 \pm 15.54$ & $77.50 \pm 6.39$ & $83.13 \pm 15.15$ \\
Interaction sex x captive managements (P-value) & $0.940^{\text {ns }}$ & $0.314^{\text {ns }}$ & $0.446^{\text {ns }}$ & $0.100^{\text {ns }}$ & $0.162^{\text {ns }}$ \\
Male x semi-captive & $318.20 \pm 15.59$ & $311.40 \pm 31.81$ & $228.30 \pm 9.88$ & $80.10 \pm 5.57$ & $79.60 \pm 3.89$ \\
Male x full captive & $330.50 \pm 42.90$ & $283.75 \pm 18.23$ & $234.75 \pm 14.71$ & $87.75 \pm 3.86$ & $80.25 \pm 4.86$ \\
Female x semi-captive & $296.07 \pm 22.34$ & $278.33 \pm 32.73$ & $208.20 \pm 13.61$ & $74.00 \pm 6.57$ & $72.00 \pm 5.73$ \\
Female x full captive & $307.25 \pm 18.13$ & $268.10 \pm 12.83$ & $208.25 \pm 11.62$ & $75.45 \pm 4.52$ & $83.70 \pm 16.49$ \\
Average & $307.96 \pm 23.34$ & $281.35 \pm 29.20$ & $214.49 \pm 15.55$ & $76.96 \pm 6.54$ & $79.00 \pm 12.10$ \\
\hline N & & & &
\end{tabular}

Note : ${ }^{\text {ns Non-significant, }}$ "significant at $\mathrm{P}<0.05,{ }^{* *}$ significant at $\mathrm{P}<0.01$
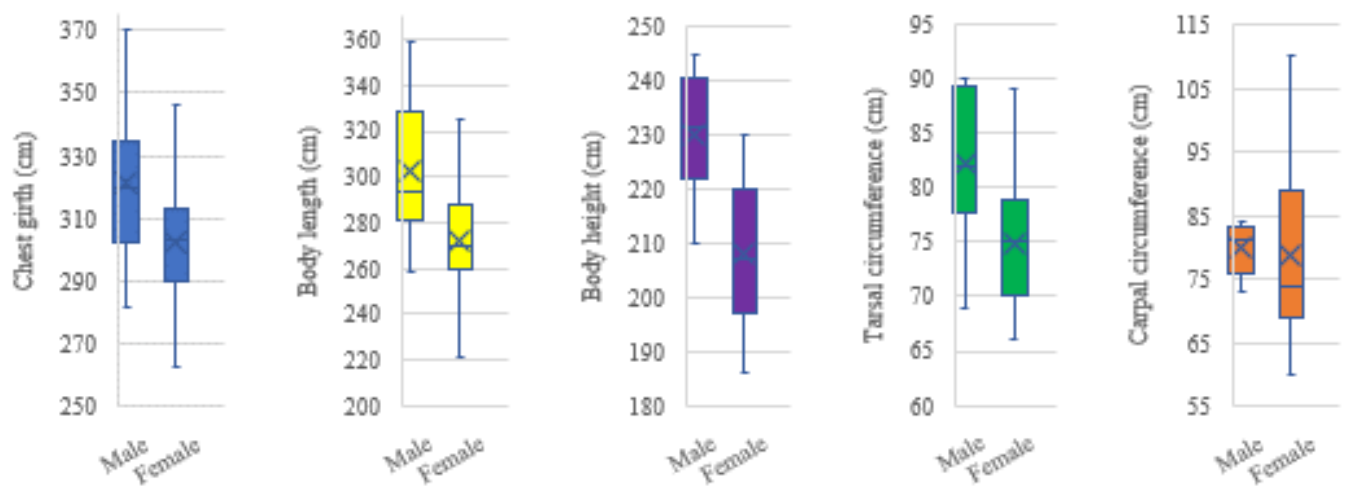

Figure 1. Boxplot of body measurements of Sumatran elephants on different sex
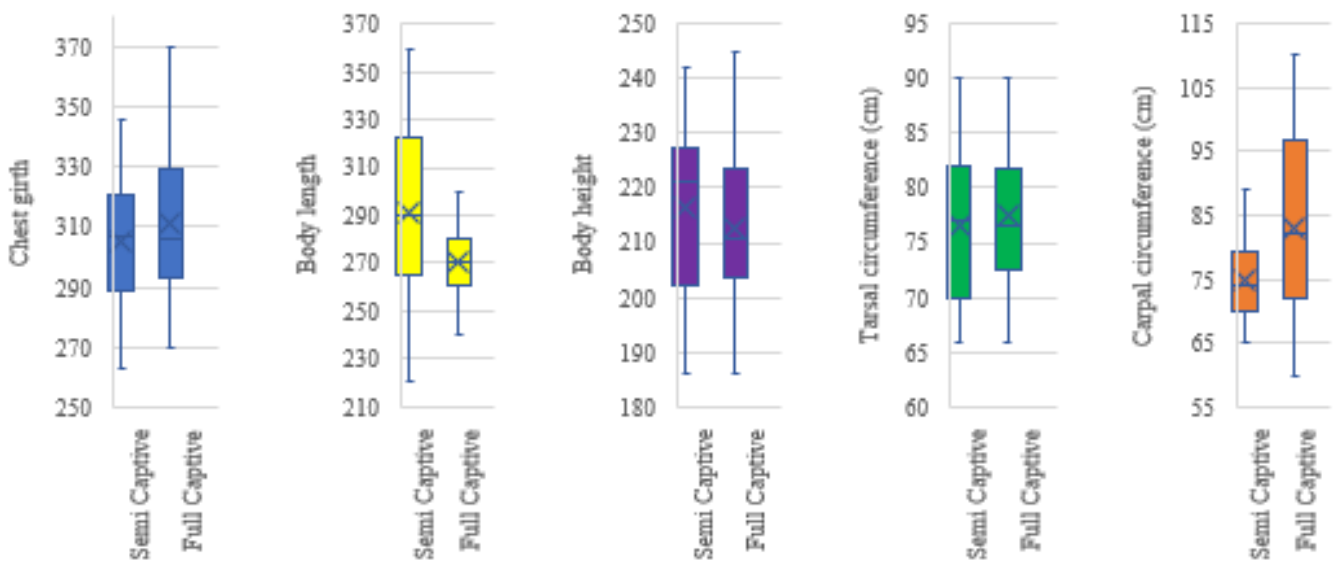

Figure 2. Boxplot of body measurements of Sumatran elephants on different captive management 
Table 1 shows the results of the differences in body parameters among Sumatran elephants based on sex and types of captivity management. In correlation with sex factors, the study showed significant results on body parameters. The size of Chest Girth (CG), Body Length (BL), Body Height (BH), and Tarsal Circumference (TC) were different between male and female Sumatran elephants ( $\mathrm{P}<0.01)$. Data were analyzed using a completely randomized factorial design with different management (semi-captive and full captive) and sex (male and female) as the factors (see Table 1). The results in sex categories (male and female) showed significant results $(\mathrm{P}<0.01)$ on Chest Girth (CG) (321.71 vs 302.46), Body Length (BL) (303.50 vs 272.49), Body Height (BH) (230.14 vs 208.23) and Tarsal Circumference (TC) (82.29 vs 74.83). However, no significant result was identified in Carpal Circumference (CC). In captivity categories, only Body Length (BL) (304.92 vs 311.13) and Tarsal Circumference (TC) (76.44 vs 77.50) had significant results $(\mathrm{P}<0.05)$. The other body measurement including Chest Girth (CG), Body Height (BH), and Carpal Circumference (CC) were not significant. In addition, the interaction between captive management and sex on body measurements showed non-significant results across variables. It is indicative of zero interaction between the type of captivity management (semi-captive and full captive) and sex (male and female) on each body measurement ( $\mathrm{CG}, \mathrm{BL}, \mathrm{BH}, \mathrm{TC}$, and $\mathrm{CC}$ ) of the captive Sumatran elephants. Different captivity managements for Sumatran elephant showed different results in Body Length (BL) and Tarsal Circumferences (TC) measurements $(\mathrm{P}<0.05)$. The other parameters including the Chest Girth (CG), Body Height (BH) and Carpal Circumferences (CC) showed no significant differences between captive Sumatran elephants in semi-captive and in full-captive management. However, the Body Length (BL) and Body Height $(\mathrm{BH})$ parameters were bigger in semi-captive than those in full captive management, which may reflect linear measurements to bone growth.

\section{Discussion}

The study of body measurement to Asian elephants (Elephas maximus), especially Sumatran elephants has three-pronged aspects. Considering the Critically Endangered species status, body measurement studies could help researchers promote the conservation of Sumatran elephants. Also, body size might link to some traits, such as male dominance, and the potential danger imposed by elephants due to their big size (Mumby et al. 2015a). At last, body size measurement is particularly useful in animal management practices, for example as a determinant of feeding program, the calculation of dose level (drug and anesthesia), nutritional status, general health, and growth evaluation. On the other hand, measuring the body weight and height or length was useful to be an indicator of skeletal growth and distinguish between determinate and indeterminate growth (Mumby et al. 2015b). The growth strategies of animals are important to understand life-history theory, such as determine the body size and influence key life-history traits (survival, development, and reproduction) (Vinicius and Mumby 2013).

The male elephants are generally larger than the female, except for the Carpal Circumference (CC). This finding confirms previous studies that sex affects body size of elephants, in fact, males are larger than females in everybody parameter. Moreover, the body growth of male elephant accelerate their growth after the puberty period and continue to gain weight throughout life it called "postpubertal growth spurt" (Chapman et al. 2016). As a result, male elephants are generally taller and almost twice as heavy as the female. The differences strategies between sexes in some species which male have a bigger body size to compete for mating opportunities (Mumby et al. 2015a). In many species, bodyweight already compared with evidence of survival and reproductive senescence (Nussey et al. 2011; Hayward et al. 2014). Growth of shoulder height Asian elephant for both male and female, being slow after sexual maturity (around 15 years old) (Mumby et al. 2015b). Based on study by Mumby et al. (2015b) showing $95 \%$ of females elephant growth is completed around sexual maturity (15-16 years old), and for males, $95 \%$ of growth body is completed at around 21 years old, however for height body around $90 \%$ achieved by 15 years old.

The contributing factors to different sizes of BL and BH include sex, the management of captivity, growth patterns, and mature frame size. These factors are related to the quality of captivity management in elephants, which are affected by food management, animal welfare, and health status. The measurements of body parameters depend on the growth patterns in each species, differ with age and sex, and potentially be affected by another factor (Chapman et al. 2016). The longitudinal monitoring of body condition is needed, because chronic stress condition is manifest in animals through effects on weight, behavior, reproduction and immunity (Mumby et al. 2015b). Negative handling in animals captivity such as slapping, pushing, shouting, and scare tactics, could reduced growth body, feed conversion efficiency, pregnancy rates because of stress response of animals (Ward and Melfi 2015). Animal welfare practices are important to make sure that elephants in good body condition, because the high level of stress could suppress immune function (Mumby et al. 2015b).

Based on the analyses, there was no interaction between sex (male and female) and captive management (semicaptive and full captive) on body measurements of captive Sumatran elephant. The wide range of ages from the samples despite being identified as adult elephants may contribute to the non-existent interaction. Mumby et al. (2015b) stated between male and female elephants differ in height body, but the pattern of height growth very similar. The difference is in female is weight levelling off soon after maximum height reached, but male weight continuing to increase throughout life (Mumby et al. 2015b). This pattern of increased weight in males already studied in species with sexual dimorphism and aggressive competition between males. Females elephants reach the peak of fecundity is around 19 years old, which is the growth of weight body nearly completed (Hayward et al. 2014). It could be a natural process to prepare the 
reproductive phase in a good condition. Bodyweight of elephants is an important indicator for body condition individuals and health status (Hile et al. 1997).

The body measurements have been developed to estimate the animal weight and particularly important to measure the size as an indicator of the body condition (Chapman et al. 2016). Unfortunately, data of elephant body size are rare due to some reasons. The techniques of direct measurements cannot be properly assessed for accuracy. On the other hand, measuring weight directly using weighing tools is more difficult for big mammals like elephants compared to measuring the body parameters and predicting with the equation (Hile et al. 1997). Many national parks in Indonesia, have no weight scale machine for elephants. The prediction of body weight in Sumatran elephants should be improved, because information on body weight and body growth are important for conservation reasons. Weight does have impact on conservation to achieve mating success in male elephant, because we should make sure that male elephants heavy enough to be able to win dominance interactions and mating (Mumby et al. 2015b).

The equation of Kurt and Garai (2007) is the most accurate fit, but it is only for infant elephants under the age of 6. Besides, Kurt and Garai (2007) provide high accuracy of equation for adult male elephants using chest girth and body height. The assessment of body measurements in elephant to predict body weight showed that both sexes (male and female) were highly correlated with chest girth (Chapman et al. 2016). It supports the results of our study that the significant result of differences in body measurements was based on sexes (male and female). Additionally, neck circumferences showed a high correlation in males but less in females, and foot circumference measurements to predict the body weight showed a poor result in females than males (Chapman et al. 2016). Hile et al. (1997) concluded that there was not a single equation based on body measurement that was ideal for all age groups in elephants. It corresponds to the study of Chapman et al. (2016) that assessed various body measurements for predicting body weight using the equation.

In conclusion, there might be no equation based on a single body measurement that was ideal for all groups of elephant based on sex, age, or captivity management. The results of this study contributed to provide scientifically the differences of parameters in body measurement based on sex (male and female) factors. The result could suggest that equation to predict the bodyweight should be created separately between male and female Sumatran elephants to enhance the accuracy for practical use in the field. Further investigation into the other contributing factors of body measurement is encouraged.

\section{ACKNOWLEDGEMENTS}

The authors would like to express their gratitude to the Indonesian Ministry of Environment and Forestry; Jawa Timur Park Conservation Institute, Batu, Indonesia;
Borobudur Park, Magelang, Jawa Tengah and the Department of Anatomy, Faculty of Veterinary Medicine, Universitas Gadjah Mada (UGM), Yogyakarta, Indonesia. We are thankful to the Veterinary Society for Sumatran Wildlife Conservation (VESSWIC) for the support in collecting samples in the field. Special thanks go to the Tropical Forest Conservation Action for Sumatera (TFCA Sumatera) Indonesia for the financial support in the field through Grant Number 6/1/2/2017/-/-/2/1/0049/. Our warmest appreciation goes to drh. Mahcmud Asvan from Gembira Loka Zoo, Yogyakarta, Indonesia for his tremendous assistance and great support, as well as all elephants' keepers. This study was supported by Universitas Gadjah Mada through Program Rekognisi Tugas Akhir (RTA) with letter number 2127/UN1/DITLIT/DIT-LIT/LT/2019 and Ministry of Research, Technology and Higher Education of Republic Indonesia through Pendidikan Magister menuju Doktor Sarjana Unggul (PMDSU) Program Batch III with Letter of Appointment Agreement Number 8/E1/KP/.PTNBH/2019 and Number 2955/UN1.DITLIT/DIT-LIT/LT/2019.

\section{REFERENCES}

Athanassiou A. 2012. A skeleton of Mammuthus trogontherii (Proboscidea, Elephantidae) from NW Peloponnese, Greece. Quat Int 255: 9-28. DOI: 10.1016/j.quaint.2011.03.030.

Azmi W, Gunaryadi D. 2011. Current status of Asian elephants in Indonesia. Gajah 35: 55-61.

Bansiddhi P, Brown JL, Thitaram C, Punyapornwithaya V, Somgird C, Edwards KL, Nganvongpanit K. 2018. Changing trends in elephant camp management in Northern Thailand and implications for welfare. PeerJ 6: e5996. DOI 10.7717/peerj.5996.

Chapman SN, Mumby HS, Crawley JAH, Mar KU, Htut W, Soe AT, Aung HH, Lummaa V. 2016. How big is it really? Assessing the efficacy of indirect estimates of body size in Asian elephants. PLoS ONE 11(3): e0150533. DOI: 10.1371/journal.pone.0150533.

de Mori B, Stagni E, Ferrante L, Vogt G, Ramsay KA, Normando S. 2019. Scientific and ethical issues in exporting welfare findings to different animal subpopulations: The case of semi-captive elephants involved in Animal-Visitor Interactions (AVI) in South Africa. Animals 9(10): 831. DOI 10.3390/ani9100831.

Graham C, von Keyserlingk MAG, Franks B. 2018. Free-choice exploration increases affiliative behaviour in zebrafish. Appl Anim Behav Sci 203: 103-110. DOI: 10.1016/j.applanim.2018.02.005.

Hayward AD, Mar KU, Lahdenperä M, Lummaa V. 2014. Early reproductive investment, senescence and lifetime reproductive success in female Asian elephants. J Evol Biol 27: 772-783. DOI $10.1111 /$ jeb. 12350 .

Hile ME, Hintz HF, Erb HN, Hintz F. 1997. Predicting body weight from body measurements in Asian elephants (Elephas maximus). J Zoo Wildl Med 28: 424-427.

Ibrahim A, Budisatria IGS, Widayanti R, Atmoko BA, Yuniawan R, Artama WT. 2020. On-Farm body measurements and evaluation of batur sheep on different age and sex in Banjarnegara regency, Indonesia. Adv Anim Vet Sci 8(10): 1028-1033. DOI: 10.17582/journal.aavs/2020/8.10.1028.1033.

Jukar AM, Lyons SK, Uhe MD. 2018. A cranial correlate of body mass in proboscideans. Zool J Linn Soc 20: 1-13. DOI: 10.1093/ZOOLINNEAN/ZLX108.

Kurt F, Garai ME. 2007. The Asian elephant in captivity: A field study. Cambridge University Press, Cambridge. DOI: 10.1017/UPO9788175968301.

Larramendi A. 2016. Shoulder height, body mass, and shape of proboscideans. Acta Palaeontol Pol 61 (3): 537-574. DOI: 10.4202/app.00136.2014.

Mumby HS, Chapman SN, Crawley JAH, Mar KU, Htut W, Thura Soe A, Aung HH, Lummaa V. 2015a. Distinguishing between determinate 
and indeterminate growth in a long-lived mammal. BMC Evol Biol 15 (1): 1-9. DOI: 10.1186/s12862-015-0487-x.

Mumby HS, Mar KU, Thitaram C, Courtiol A, Towiboon P, Min-Oo Z, Htut-Aung Y, Brown JL, Lummaa V. 2015b. Stress and body condition are associated with climate and demography in Asian elephants. Con Phys 3: 1-14. DOI 10.1093/conphys/cov030.

Nussey DH, Coulson T, Delorme D, Clutton-Brock TH, Pemberton JM, Festa-Bianchet M, et al. 2011. Patterns of body mass senescence and selective disappearance differ among three species of free-living ungulates. Ecology 92: 1936-1947. DOI: 10.1890/11-0308.1.

Reilly J, Sukatmoko P. 2002. The elephant training centre at Way Kambas National Park, Sumatra: A review of its operations and recommendations for the future. Gajah 21: 1-40.

Rossman ZT, Padfield C, Young D, Hart LA. 2017. Elephant-initiated interactions with humans: Individual differences and specific preferences in captive African elephants (Loxodonta africana). Front Vet Sci 4: 1-10. DOI: 10.3389/fvets.2017.00060.

Sakamoto M. 2017. Recent topics on CITES related to Asian elephants in particular. Gajah 47: 42-44.

Tilson R, Soemarna K, Ramono W, Sukumar R, Seal U, Traylor-Holzer K, Santiapillai C. 1993. Asian Elephant in Sumatra: Population and Habitat Viability Analysis Workshop, Bandar Lampung, Indonesia 8-
10 November 1993. Indonesian Forest Protection and Nature Conservation, Jakarta

Sulandari S, Zein MSA 2012. Mitochondrial DNA variation of the Sumatran elephant populations in Sumatra, Indonesia. Biotropia 19 (2): 92-102. DOI: $10.11598 / \mathrm{btb} .2012 .19 .2 .250$.

Vinicius L, Mumby HS. 2013. Comparative analysis of animal growth: A primate continuum revealed by a new dimensionless growth rate coefficient. Evolution 67: 1485-1492. DOI 10.1111/evo.12043.

Wakchaure R, Ganguly S. 2016. Captive breeding in endangered wildlife: A review. J Biol Sci Opinion 4 (5): 186-187. DOI: 10.7897/23216328.04544.

Ward SJ, Melfi V. 2015. Keeper-animal interactions: Differences between the behaviour of zoo animals affect stockmanship. PLoS ONE 10 (10): e0140237. DOI:10.1371/journal.pone.0140237.

Wibowo DS, Widiyanti R, Asvan M, Restanti PD, Wijayanto H. 2021. Short Communication: Molecular study on mt-DNA COX2 gene of Sumatran elephant (Elephas maximus sumatranus). Biodiversitas 22 (2): 1063-1068. DOI: 10.13057/biodiv/d220263.

Wijeyamohan S, Sivakumar V, Read B, Schmitt D, Krishnakumar S, Santiapillai C. 2012. A simple technique to estimate linear body measurements of elephants. Curr Sci 102 (1): 26-28. 